It will be convenient to reproduce Dr. Venn's figures in a separate table, neglecting the second decimal :-

Head Products.

\begin{tabular}{|c|c|c|c|c|c|c|}
\hline Ages. & $\begin{array}{c}\text { Class A. } \\
\text { "High } \\
\text { honour"men. }\end{array}$ & 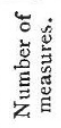 & $\begin{array}{l}\text { Class B. } \\
\text { The remain- } \\
\text { ing " hon sur" } \\
\text { men. }\end{array}$ & 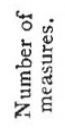 & $\begin{array}{c}\text { Class C. } \\
\text { " Poll " men. }\end{array}$ & 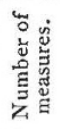 \\
\hline I9 & $24 I^{\prime} 9$ & 17 & $237^{\circ} I$ & 70 & $229^{\circ} 1$ & 52 \\
\hline 20 & $244^{\prime} 2$ & 54 & $237^{\circ} 9$ & 149 & $235^{\circ} \mathrm{I}$ & 102 \\
\hline $2 I$ & $24 I^{\circ} 0$ & 52 & $236 \cdot 4$ & I 17 & $240 \cdot 2$ & 79 \\
\hline 22 & $248 \cdot 1$ & 50 & $241 \cdot 7$ & 73 & $240^{\circ} 0$ & 66 \\
\hline 23 & $244^{\circ} 6$ & 27 & $239^{\circ} 0$ & 33 & 2350 & 23 \\
\hline 24 & $245 \cdot 8$ & 25 & $25 \mathrm{I} \cdot 2$ & 14 & $244^{\circ} 4$ & 13 \\
\hline $\begin{array}{l}25 \\
\text { and } \\
\text { up- }\end{array}$ & $248 \cdot 9$ & 33 & $239^{\circ} I$ & 20 & 2435 & 26 \\
\hline & & $25^{8}$ & & 476 & & 361 \\
\hline
\end{tabular}

The figures in the table are thrown into diagrams in Figs. I., II., and III., in which curves are also drawn to interpret what seems to be their significance. The great irregularity in Fig. II., corresponding to the age of twentyfour, may be fairly ascribed to the smallness of observations, only thirteen in number, on which it is founded. The three resultant curves are shown by themselves in Fig. IV., where they can be easily compared. It will then be seen that the $\mathrm{A}$ and $\mathrm{C}$ curves are markedly different, and that the $B$ curve is intermediate. Accepting these curves as a true statement of the case-and they are beyond doubt an approximately true statement-we find that a "high honour" man possesses at the age of nineteen a distinctly larger brain than a "poll" man in the proportion of $24 \mathrm{I}$ to 230.5 , or one that is almost 5 per cent. larger. By the end of his College career, the brain of the "high honour" man has increased from $24 \mathrm{I}$ to 249 ; that is by 3 per cent. of its size, while the brain of the "poll" man has increased from 230 ' 5 to 244.5 , or 6 per cent.

Four conclusions follow from all this :-

(I) Although it is pretty well ascertained that in the masses of the population the brain ceases to grow after the age of nineteen, or even earlier, it is by no means so with University students.

(2) That men who obtain high honours have had considerably larger brains than others at the age of nineteen.

(3) That they have larger brains than others, but not to

Length $\times$ Breadth $\times$ Height of Head, in inches, of Cambridge Cniversity Men at different Ages (from Dr. Venn's Tabes).

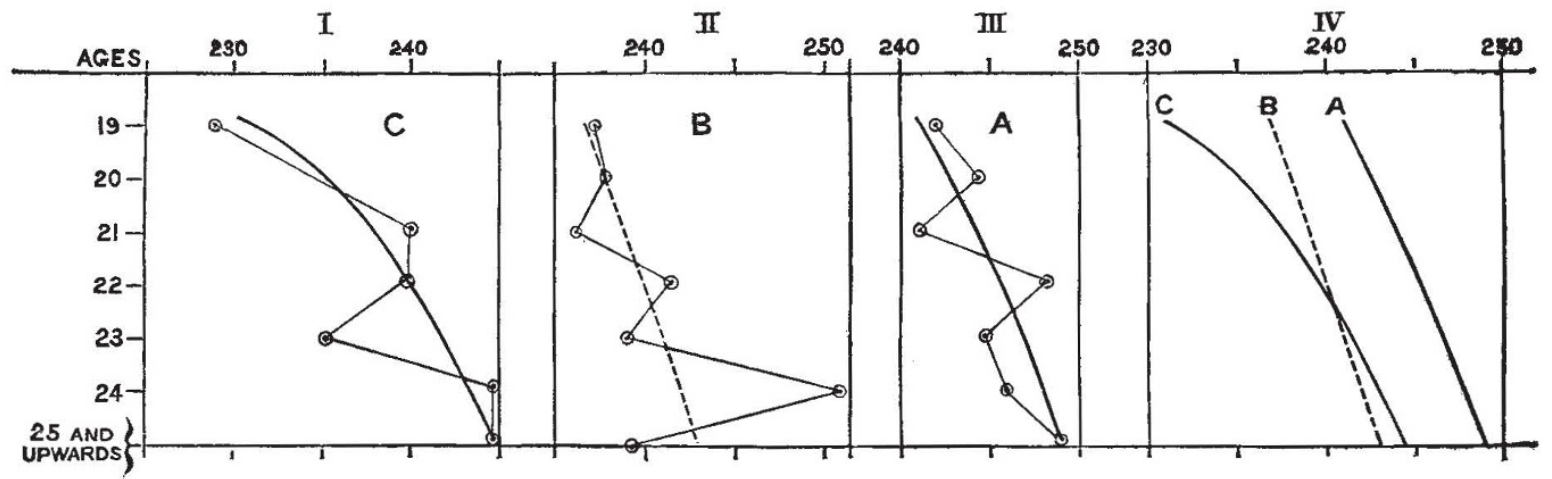

A, First Class Men; B, Honour Men, not First Class ; C, Pull Men.

the same extent, at the age of twenty-five; in fact their predominance is by that time diminished to one-half of what it was.

(4) Consequently "high honour" men are presumably, as a class, both more precocious and more gifted throughout than others. We must therefore look upon eminent University success as a fortunate combination of these two helpful conditions.

\section{PHOTOGRAPH OF THE EYE BY FLASH OF MAGNESIUM.}

THE effect of complete obscurity on the normal pupil 1 has hitherto been seen only by the light of electric discharges, which allowed of no measurements.

MM. Miethe and Gaedicke, by their invention of the well-known explosive magnesium mixture, have furnished us with a simpler method. A photograph of the eye can be taken in a perfectly dark room, showing the pupil fully dilated, as its reaction does not begin until after exposure.

Mr. Miethe, astronomer at the Potsdam Observatory, himself at my suggestion undertook to execute the accompanying photograph of a normal eye, life-size, after a quarter of an hour's rest in a carefully darkened room. The pupil was found to measure $10 \mathrm{~mm}$. horizontally (the breadth of the cornea being $13 \mathrm{~mm}$.). A reflection of the flash is seen on the cornea.

This kind of photography may prove a new and valuable method for many other branches of scientific

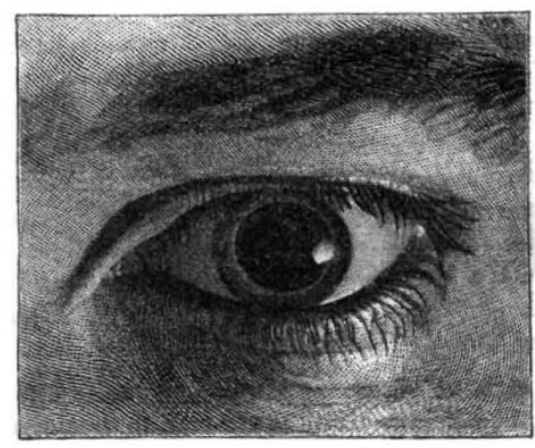

research, but it is of especial utility to ophthalmology, as the eye, by its mobility and sensitiveness, has hitherto been a most difficult subject for the camera.

Claude du Bois-Reymonrac 